\title{
Sanat Eğitiminde Sürdürülebilirlik ve Çevre Eğitimi Üzerine Bir Çalışma ${ }^{1}$
}

Nuray MAMUR ${ }^{2}$

Geliş Tarihi: $2017-05-23$

Kabul Tarihi: 2017-11-01

Öz

$\mathrm{Bu}$ araştırmada sanat yoluyla çocukların kendilerini, toplumsal çevreyi ve doğayı keşfetmelerini sağlamaya dönük etkinlikler sürdürülebilirlik temelinde geliştirilmiş ve geliştirilen etkinliklerin çocuklara katkısını incelemek amaçlanmıştır. Araştırmanın katılımcıları 11 ilkokul 4. sınıf öğrencisi ve 9 ortaokul 5. Sınıf öğrencisi olmak üzere 10-11 yaş gurubu toplam 20 öğrencidir. Araştırma verileri her etkinlikten sonra öğrencilerin doldurduğu öz değerlendirme yazıları ve süreç değerlendirme formuyla toplanmış, içerik analizi ile çözümlenmiştir. Araştırma bulguları sürdürülebilir gelişim temelli sanat etkinliklerinin; sanat ve bilim, sanat ve doğa arasındaki karşılıklı etkileşimi anlama, atık malzemelerin yeniden ve estetik bir biçimde değerlendirilmesi ve çevresel bozulmaya dair farkındalığı artırdığını göstermiştir. Araştırma sonunda sürdürülebilir sanat etkinliklerinin çevre üzerine yeni fikirlerin ve değerlerin keşfedilmesi konusunda öğrencilere katkı sağladığ 1 görülmüştür.

Anahtar Kelimeler: Sürdürülebilir gelişim, Sürdürülebilir gelecek, Ekolojik Ayak izi, Ekoloji temelli sanat eğitimi, Görsel sanatlar eğitimi

\footnotetext{
${ }^{1}$ Bu araştırma 20-22 Nisan 2017 tarihleri arasında Pamukkale Üniversitesi'nde düzenlenen Pamukkale Üniversitesi 1. Uluslararası Sanat Eğitimi Sempozyumu’nda sözlü bildiri olarak sunulmuştur. ${ }^{2}$ Doç. Dr., Pamukkale Üniversitesi, Eğitim Fakültesi, Güzel Sanatlar Eğitimi Bölümü, Denizli, nmamur@pau.edu.tr
} 


\title{
A Study on Sustainability and Environmental Education in Art Education
}

\begin{abstract}
In this study, activities that aim children to discover themselves, social environment and environment through art were developed based upon sustainability and it was aimed to figure out the effects of these activities on children. There were 20 students between the ages of 1011 in the study. 11 of the participants were $4^{\text {th }}$ grade students and 9 of them were $5^{\text {th }}$ grade students. Research data were collected by self-assessment essays written by students and process evaluation forms filled by the students after each activity and analyzed by content analysis. Research findings showed that sustainable development based on art activities, increased the understanding of the interactions between art and science, art and nature, recycling waste materials in a new and aesthetic way; and environmental deterioration awareness. As a result of the study, it was observed that sustainable art activities contribute to students in terms of creating new ideas and realizing the value of nature.
\end{abstract}

Keywords: Sustainable development, Sustainable future, Ecology based art education, The ecological footprint, Visual arts education 


\section{Giriş}

Dünyanın sağlığını tehdit eden çevresel sorunların kapsamı gün geçtikçe artıyor. nsanın doğa üzerindeki geri döndürülemez tahribatı doğal kaynakların tükenmesi, buzulların erimesi, içme suyu kaynaklarının kirlenmesi, deniz seviyesinin yükselmesi, ekosistemde aksamalar ve yeni hastalıklar gibi pek çok sorunu beraberinde getirmiştir. 20. Yüzyıl'ın ikinci yarısından itibaren fark edilmeye başlayan bu tahribata yönelik önlemler ancak 1970’lerden sonra çok boyutlu olarak tartışılmaya başlanmıştır. Çevre, toplum ve ekonomi ekseninde sürdürülebilir bir yolla doğada yaşamı öğrenme kültürel bir sorumluluk olarak daha fazla vurgulanır hale gelmiştir. Dolayısıyla son yıllarda sürdürülebilirlik gelecek, üzerine düşünme biçimi olarak Birleşmiş Milletlerin kapsayıcı bir paradigması haline gelmiştir (United Nations Educational, Scientific and Cultural Organization, [UNESCO], 2012).

Sürdürülebilirlik "zaman içinde muhafaza edilebilir olan” (Heinberg, 2016, s.27) ya da "sürekliliğị" ifade eden bir kavram olarak son yıllarda sıklıkla karşımıza çıkmaya başlamıştır. Günümüzde yeni bir kavram gibi algılansa da Heisberg'e (2016) göre eski devirlerin ve yerli halkların birçoğunun geleneğinde bulunmaktadır. Birleşmiş Milletler sürdürülebilirliği dünyanın daha fazla sürdürülebilir kılınması için uzun soluklu bir amaç olarak görmektedir.

"Sürdürülebilirlik", gelişim kavramı ile birleştiğinde ise çoğunlukla değişim olarak zihinde belirmektedir. Yani sürdürülebilir gelişim olması için ilerici olumlu bir değişimin olması beklenmektedir. Dünya Çevre ve Kalkınma Komisyonu’nun 1987 tarihli “Ortak Geleceğimiz" (Bruntland report) raporunda "Sürdürülebilir Gelişim” “mevcut kuşakların ihtiyaçlarını gelecek kuşakların kendi ihtiyaçlarını karşılayabilirliklerini riske atmadan temin eden” bir kalkınma tarzı olarak tanımlanmıştır. Günümüzde "Sürdürülebilir Gelişim ya da Kalkınma" sürdürülebilir tarım, sürdürülebilir üretim ve tüketim, sürdürülebilir eğitim, sürdürülebilir demokratik toplum, sürdürülebilir tasarım gibi içine pek çok olguyu alan geniş bir yelpazede ele alınmaktadır.

Sürdürülebilir kalkınma insanların doğayla uyumlu, sağlıklı ve verimli bir hayatı hak etmesi üzerine kuruludur. Birleşmiş Milletler sürdürülebilir kalkınmayı “Toplum”, "Çevre” ve "Ekonomi" boyutlarının birbirinin içine geçtiği çemberin kesişme alanı olarak görselleştirmiştir (The United Nations Economic Commission for Europe, 2009). Bunun anlamı en basit örneğiyle şudur: Müreffeh bir toplum olabilme ya da toplumdaki yaşam kalitesini yükseltme; sağlıklı ve güvenilir yiyecek, su tüketimi ile temiz hava solumayı 
gerektirir. Bu da ancak sağlıklı bir çevreyle mümkündür. Yani çevreyi koruma, sürdürülebilir kalkınma sürecinin önemli bir parçasıdır ve ondan insanın yalıtılması düşünülemez.

Ancak sürdürülebilirlik paradigması içinde çevreyi koruma ve iyileştirme dışında temel özgürlükler, insan hakları, eşitlik gibi birçok değer ile çevresel, sosyal, ekonomik ve politik bağlamda karmaşık ve çözümü oldukça zor konular bulunmaktadır. Örneğin; fakirlik, insan sağlığı, iklim değişikliği, kuraklık, toplumsal adalet gibi... Bu konular oldukça karmaşıktır ve uzun soluklu çözümleri gerektirir (UNESCO, 2012). Bu nedenle Birleşmiş Milletler sürdürülebilir kalkınmanın eğitimle ilişkilendirilmesini talep etmiş ve "Sürdürülebilir Kalkınma için Eğitim” (Education for Sustainable Development-ESD) vizyonunun her eğitim programına yerleşmesi için 2005-2014 yılları arasını "Sürdürülebilir Kalkınma çin Eğitim On Y1lı" olarak ilan etmiştir (UNESCO, 2005). Bu bağlamda son yıllarda UNESCO'nun uluslararası sanat eğitimi derneklerini (InSEA, IDEA, ISME, WDA) birleştirerek kurduğu Dünya Sanatlar Eğitimi Birliği "Sürdürülebilir Kalkınma çin Sanat Eğitimi” teması bağlamında biyolojik, sosyal ve kültürel çeşitliliğe duyarlılığı artırma, toplumsal adalet, ekolojik ve çevresel farkındalığı geliştirme konusunda sanat eğitimi programlarının yapılandırılması gerekliliğine işaret etmeye başlamıştır.

Aslında 1970'lerden sonra sanat dünyasında sürdürülebilirliği destekleyen pek çok uygulama görülmektedir. Bafra ve Colombo’a (2016) göre sanattaki doğa temsilleri bilhassa II. Dünya savaşı sonrasında dönüşüme uğramıştır. Doğanın sanattaki temsili de doğaya dair toplumsal ve politik algılarla doğrudan bağlantılı hale gelmiştir (Bafra ve Colombo, 2016). Günümüzde çağdaş sanatçıların önemli bir bölümünün sanat ve ekolojiyi ilişkilendirme noktasında farklı yorumlara gittiği görülmektedir. Örneğin; sosyal ekoloji, eko feminizm ve ekolojik restorasyon gibi temalar dünya ve çevreye dönük sorunların farklı bağlamlarda ele alındığı yaklaşımlardır (Neperud, 1997). Strankiewicz ve Krug (1997) pek çok sanatçının sağlıklı yaşam biçimlerinin nasıl sürdürülebileceğini keşfetmek için sanatlarını kullandığından bahsetmektedir. Örneğin; Mel Chin 1990'da gerçekleştirmiş olduğu “Revival Field” adlı bir çalışmasında kimyasal atıklarla kirlenmiş bir toprağı arındırarak yeniden yaşamı başlatmayı hedeflemiştir. Andy Goldsworthy ise eserlerini doğadan seçtiği hassas, kısa ömürlü materyalleri yine doğanın yok edebileceği biçimde doğanın içinde düzenleyerek oluşturmuştur (Hollis, 1997). Goldsworthy gibi pek çok çağdaş sanatçı doğadaki sıra dış1 materyallerle çalışmayı tercih ederken, bazı sanatçıların atık materyalleri yeniden kullanarak izleyiciye yeni bir bakış açısı sunduğu görülmektedir. Örneğin; Tressa Prisbrey Kaliforniya Simi Vadisi’nde geri dönüşüm materyalleri ile atık şişelerden bir köy yaratmıştır. Sanatçı 
köyün tüm yapılarında, kaldırımları da dahil olmak üzere geri dönüşüm malzemesi kullanmıştır. 1956 ve 1981 yılları arasında gerçekleşen bu uzun soluklu çalışmada hemen hemen 10000 şişe kullanılmıştır. Zamanla gerçek boyutlardaki "şişe köy" halkın ilgisiyle geri dönüşüm müzesine dönüşmüştür. Bazı çağdaş sanatçıların ise kültürel bir restorasyonla ilgilendiği görülmektedir. Eserlerinde halkı bilinçlendirecek şekilde metin ve simgeleri kullanmayı tercih etmişler ya da performans gösterileri ile geniş katılımlı aktivitelere yönelmişlerdir. Elbette sanatçı anlatımlarını burada pek çok örnekle çeşitlendirmek mümkündür. Nitekim sanat dünyasındaki bu çeşitlilik sürdürülebilir kalkınma için eğitimle bütünleştirilebilir konumdadır. Çünkü UNESCO’nun kaliteli eğitim vizyonunda çeşitlilik; öğrenme ve düşünme kapasitesini artıran bir unsur olarak nitelendirilmektedir.

UNESCO'nun (2012) eğitimciler için hazırladığı "Education for Sustainable Development" adlı rehber kitapta sürdürülebilirliğin her disiplin tarafından ele alınabileceği ve disiplinler arası olarak da eğitimde konumlandırılabileceği belirtilmektedir. Öğreneni temel alma, onun bilgi ve deneyimleri kabul etme ve onun farklı ihtiyaçları doğrultusunda farklı öğrenme ve öğretme tekniklerini kullanma sosyal bir eşitlik biçimi olarak sürdürülebilir kalkınma eğitiminin temel unsurlarıdır. Ayrıca çocukların ve gençlerin yaratıcı ve daha iyi bir geleceği hayal edebilmeleri için tartışma, analiz, değerlendirme, sanat, drama ve oyundan yararlanılması talep edilmektedir.

UNESCO (2012) Sürdürülebilir Kalkınma Eğitimi üzerine eğitimcilere öğretim etkinliklerinin yapılandırılmasında beş önemli bileşenle bir çerçeve planı sunmaktadır. Bunlar; bilgi, konu, beceri, bakış açısı ve değerler olarak ele alınmaktadır. Bu yapıda bilgi; insanların bir şeyleri anlamaları için doğa bilimleri, sosyal bilimler ve insan bilimlerinin temel bilgisini alması içindir. Konu; tarım, biyoçeşitlilik, tüketim alışkanlıkları, iklim değişikliğgi, taze su kaynaklarının korunması, toplumsal cinsiyet, toprağın kullanımı, toplumsal adalet gibi sürdürülebilir dünyaya hizmet edebilecek birçok konuyu içermektedir. Beceri; sürdürülebilir bir yaşam kurmak ve yaşamı sürdürülebilir kılmak çerçevesinde eleştirel düşünme yeterliliği geliştirmek içindir. Burada özellikle diğer insanların bakış açılarını anlamak için çoklu bakış açılarını kullanma, farkındalıktan bilgiye ve eyleme geçiş, başkaları ile işbirliği yapabilme ve sanat ve çevreye duyarlılık gibi becerileri geliştirmek hedeflenmektedir. Bakış açısı; yerel sorunların küresel bağlamda anlaşılması ve yerel sorunların çözümü ile küresel sonuçlara ulaşmaya odaklanma ve bir yargıya varmadan önce farklı bakış açılarından düşünme üzerine kurulur. Değerler ise, kişisel değerler, toplumsal değerler ve dünya üzerindeki diğer insanların değerleri olarak dünyadaki tüm yaşam ve çeşitliliğe saygı, mevcut ve gelecek nesiller 
arasındaki eşitlik, toplumsal cinsiyet eşitliği ve hoşgörü kültürünü destekleyecek katılımcı, sürdürülebilir ve barışçıl yaklaşımları ifade etmektedir.

Türkiye'de sürdürülebilir kalkınma eğitimi üzerine son 10 yılda kuramsal ve uygulama bazında araştırmalar (Alkış, 2007; Öztürk Demirtaş, 2011; Kaya ve Tomal, 2011, Tanrıverdi, 2009; Teksöz, Şahin ve Ertepınar, 2010) artmıştır. Yapılan bu araştırmaların ise sosyal bilgiler, coğrafya ve öğretmen eğitiminde yoğunlaştığı ve ağırlıklı olarak program incelemesi ya da sürdürülebilirliğe ilişkin farkındalık düzeyini belirlemeye yönelik olduğu görülmektedir. Dolayısıyla eğitimcilere ve sanat eğitimcilerine yol göstermek açısından sürdürülebilir kalkınma eğitiminin uygulamaya dönük yaklaşımlarına daha fazla odaklanılması gerektiği ortadadır.

$\mathrm{Bu}$ araştırmada sanat yoluyla çocukların kendilerini, toplumsal çevreyi ve doğayı keşfetmelerini sağlamaya dönük etkinliklerin sürdürülebilir kalkınma eğitimi temelinde nasıl geliştirilebileceği ve geliştirilen etkinliklerin öğrencilere katkılarını belirlemek amaçlanmıştır. $\mathrm{Bu}$ amaç doğrultusunda aşağıda yer alan sorulara yanıt aranmıştır.

1- Sürdürülebilir Kalkınma Eğitimi görsel sanatlar eğitimi öğretim uygulamalarına nasıl dâhil edilebilir?

2- Sürdürülebilir kalkınma eğitimi bağlamında hazırlanan sanat aktivitelerinin öğrencilere katkısı nelerdir?

\section{Yöntem}

$\mathrm{Bu}$ araştırmada, UNESCO tarafından çerçevesi çizilen sürdürülebilir kalkınma eğitiminin temel felsefesi bağlamında görsel sanatlar etkinlikleri tasarlanmasına ve hazırlanan etkinliklerin öğrencilere sağladı̆̆ı katkılara odaklanılmıştır. Araştırma, görsel sanatlar öğretmenlerine bir sanat dersini sürdürülebilirlik bağlamında nasıl yapılandırabilecekleri ve etkinlikleri nasıl tasarlayacaklarına ilişkin bir kılavuz verilmek istenildiği için eylem araştırmasıdır.

Öğretmen araştırması olarak da adlandırılan "eylem araştırması", eğitim örgütlerinde çalışanların kendi durumlarına özgü problemlerine çözüm üretmede veya kendilerini yenileyebilmeleri için kullanılan yöntemlerden birisidir (Beyhan, 2013). Bu bağlamda sürdürülebilir kalkınma eğitiminden yola çıkarak sanat derslerine aktif ve anlamlı bir öğrenmenin nasıl yaratılabileceği ve tasarlanan eğitim etkinliklerinin öğrencilerin doğayı, toplumu ve kendilerini keşfetmede nasıl bir katkı sağlayacağına odaklanılmıştır. 
Araştırma bilim, sanat ve drama etkinliklerinden oluşan, çocukların bilim ve sanat eğitimi yoluyla kendilerini, toplumsal çevreyi ve doğayı keşfetmelerini sağlayarak sürdürülebilir gelişimi desteklemeyi amaçlayan bir proje kapsamında Denizli ilinde özel bir kuruluşun Eğitim ve Kültür Vakfı bünyesinde gerçekleştirilmiş ve desteklenmiştir. Proje 1 Milli Eğitim Müdürlüğü onayı ile çoğunlukla düzenli geliri olmayan ya da askeri geçim düzeyinin altında yaşayan ailelerin yaşadığı bir bölgeden seçilen iki okuldan toplam 20 öğrenci (12 Kı, 8 Erkek öğrenci) ile yürütülmüştür. Katılımcı öğrencilerden 11'i ortaokul 5. Sınıf, 9'u ilkokul 4. sınıf öğrencisidir. Proje 2016 Mart ayı sonu itibariyle başlamış, Nisan ve Mayıs ayında bilim ve sanat atölye çalışmaları ile yaratıcı drama etkinlikleri olarak gerçekleştirilmiştir. Ancak bu araştırma, projenin sanat etkinlikleri bağlamında elde edilen veriler ile sınırlandırılmıştır. Projenin sanat etkinlikleri UNESCO tarafından çerçevesi çizilen sürdürülebilir kalkınma eğitiminin temel felsefesi bağlamında tasarlanmış; çocukların fiziki, kültürel ve doğal çevreye duyarlılığını artırmaya odaklanmış toplam 10 atölye etkinliğinden oluşmuştur.

\section{Veri Toplama Süreci ve Araçları}

Doküman ncelemesi: Bu araştırma için öncelikle UNESCO tarafından eğitimcilere rehber olması için hazırlanan “Education for Sustainable Development Sourcebook” kaynak kitap incelenmiştir. Kaynak kitapta çerçevesi çizilen sürdürülebilir kalkınma eğitiminin üç sacayağını oluşturan çevre, toplum ve ekonomi bağlamında toplam 10 sanat etkinliği oluşturulmuştur. $\mathrm{Bu}$ etkinliklerden sekizi atölye etkinliği, birisi Doğa ve Çevre Vakfı (DOÇEV) ormanında, bir tanesi de özel kuruluşa ait sanat galerisinde bir sanatçı ile söyleşi şeklinde planlanmıştır. Etkinliklerin her biri okul sonrası 90 dakikalık bir program kapsamında gerçekleştirilmiştir. Her etkinlik sonrası öğrencilere öz değerlendirme formu, etkinliklerin bitiminde ise öğrencilere tüm çalışma sürecini değerlendirdikleri süreç değerlendirme formu verilmiştir.

Öz değerlendirme formu: Proje süresince öğrenci kazanımlarını belirleyebilmek ve etkili öğretim süreci planlayabilmek adına öğrenci öz değerlendirme yazılarından yararlanılmıştır. Öğrencilere her günün sonunda o günkü etkinliğe ilişkin öğrendikleri, etkinlikler kapsamında duygu ve düşüncelerinin neler olduğu ve etkinliklerin yaşamlarına neler kattığını ya da katacağını belirten yansıtıcı öz değerlendirme yazıları yazmaları istenmiştir. Böylece öğrencilerin sanat etkinliklerinden elde ettiği kazanımlar onların yansıtıcı düşünceleriyle ortaya çıkartılmıştır. Öz değerlendirme kapsamında öğrencilere rehberlik eden sorulardan 
bazıları şöyledir: "Bugün öğrendiğiniz bilgilerden size göre en anlamlısı nedir?”, "Bugün öğrendiğiniz bilgileri günlük yaşantınızla nasıl ilişkilendirebilirsiniz?”, "Bugün yaptığın sanat etkinliğinin size katkısı neler oldu, size neler öğrettiğini düşünüyorsun?”

Süreç değerlendirme formu: Sanat programının öğrencilere katkılarını değerlendirmek için proje sonrası bir süreç değerlendirme anketi düzenlenmiştir. Değerlendirme formu yarı yapılandırılmış ve açık uçlu sorular ile oluşturulmuş ve tüm etkinliklerin bitiminde uygulanmıştır. Süreç değerlendirme formunda yer alan sorulardan bazıları şöyledir: "Çevremizi ve doğayı niçin korumalıyız?", "Sanatsal ürünler yaparken çevremizden ve doğadan nasıl yararlanabiliriz?", "Sanat etkinliklerinde en çok neleri sevdiniz?", "Sanatı doğayı ve çevreyi korumak için nasıl kullanabiliriz?”, “Öğrenme ortamı sizin için nasıldı?”, "Sanat etkinliklerinin size sağladığı faydalar nelerdir?"

\section{Verilerin Analizi}

Araştırmada öz değerlendirme ve süreç değerlendirme formu yoluyla elde edilen veriler içerik analizi ile çözümlenmiştir. çerik analizi kullanıldığı bağlama ve metinlere göre anlamlı ve geçerli çıkarımlar yapmaya odaklanan bilimsel bir araştırma yöntemidir (Krippendorff, 2004). $\mathrm{Bu}$ bağlamda veri analizine uygulama süreci esnasında başlanmış ve elde edilen veriler çerçevesinde oluşturulan her etkinlik araştırmanın amacı doğrultusunda yeniden düzenlenmiştir. Araştırma sonunda geçerli çıkarımlar yapabilmek için tüm veri seti farklı zaman aralıklarında tekrar tekrar okunmuştur. Bu okumalar esnasında olası kod ve kod kategorileri belirlenmiştir. Ardından veri setinin bir bölümünde belirlenen kodların işlerliği denenmiş ve elde edilen kodlar çerçevesinde kodlama güvenirliğini sağlamak amacıyla doktora tez çalışmasını nitel veriyle yürütmüş olan bir alan uzmanından veriyi kodlanması istenmiştir. Sonrasında her iki kodlayıcı tarafından yapılan kodlamalar karşılaştırılarak kodlama güvenirliği hesaplanmıştır. Miles ve Huberman'ın (1994, s.64) görüş birliği ve görüş ayrılı̆̆ı formülüne göre yapılan hesaplama sonucunda puanlayıcılar arası güvenirlik katsayıs1 \%80 çıkmıştır.

\section{Bulgular}

Araştırmada “Sürdürülebilir Kalkınma Ĕ̆̈itimi” sanat e ğitimi öğretim uygulamalarına nasıl dâhil edilebilir? sorusu bağlamında ders içeriklerinin oluşturulabilmesi için UNESCO tarafından çerçevesi çizilen sürdürülebilir kalkınma eğitiminin temel yapısı; 1) Sürdürülebilir gelişimin kültürel boyutları, 2) Sürdürülebilir gelişimin değerleri ve 3)Sürdürülebilir kalkınma 
Tablo 1. Ders izlencesi

\begin{tabular}{|c|c|c|c|c|}
\hline Hafta & Etkinlik & Materyaller & $\begin{array}{l}\text { Sürdürülebilir } \\
\text { Kalkınma Eğitimi } \\
\text { temel değerleri }\end{array}$ & Konu \\
\hline 1.Hafta & $\begin{array}{l}\text { Kendi kültürel } \\
\text { değerlerini keşfet, taşa } \\
\text { naklet }\end{array}$ & $\begin{array}{l}\text { Doğal taşlar } \\
\text { Kültürel } \\
\text { Motifler }\end{array}$ & $\begin{array}{l}\text { Kültürel } \\
\text { sürdürülebilirliği } \\
\text { destekleme }\end{array}$ & $\begin{array}{l}\text { Kültürel } \\
\text { değerler }\end{array}$ \\
\hline 2.Hafta & $\begin{array}{l}\text { Su ile sanat, köpük ile } \\
\text { sanat }\end{array}$ & $\begin{array}{l}\text { Geleneksel } \\
\text { sanatlardan } \\
\text { ebru, suyun } \\
\text { üstünde } \\
\text { resimler }\end{array}$ & $\begin{array}{l}\text { Doğal kaynakları } \\
\text { koruma } \\
\text { Nesiller arası eşitlik }\end{array}$ & $\begin{array}{l}\text { Dünyada suyun } \\
\text { kullanımı }\end{array}$ \\
\hline 3.Hafta & $\begin{array}{l}\text { Ben bastım olmuş } \\
\text { mu? }\end{array}$ & $\begin{array}{l}\text { At1k } \\
\text { materyaller }\end{array}$ & $\begin{array}{l}\text { Çevreyi koruma ve } \\
\text { onu iyileştirme }\end{array}$ & Biyoçeşitlilik \\
\hline 4.Hafta & $\begin{array}{l}\text { Arcimboldo } \\
\text { yediklerimle } \\
\text { otoportrem }\end{array}$ & $\begin{array}{l}\text { Yenilebilir } \\
\text { materyaller }\end{array}$ & $\begin{array}{l}\text { Doğadaki tüm yaşam } \\
\text { biçimlerine saygı }\end{array}$ & $\begin{array}{l}\text { Toprağın } \\
\text { kullanımı }\end{array}$ \\
\hline 5.Hafta & $\begin{array}{l}\text { Dale Chihuly ile } \\
\text { doğanın çiçekleri }\end{array}$ & $\begin{array}{l}\text { Isı ile } \\
\text { biçimlendirilmi } \\
\text { ş plastik atık } \\
\text { materyaller }\end{array}$ & $\begin{array}{l}\text { Doğanın } \\
\text { güzelliklerini } \\
\text { güvenceye alma }\end{array}$ & Biyoçeşitlilik \\
\hline 6.Hafta & Atıktan sanata & $\begin{array}{l}\text { Plastik, cam, } \\
\text { metal ve } \\
\text { elektronik } \\
\text { atıklar }\end{array}$ & $\begin{array}{l}\text { Nesiller arası eşitlik } \\
\text { Çevreyi koruma ve } \\
\text { onu iyileştirme }\end{array}$ & $\begin{array}{l}\text { Geri dönüşüm } \\
\text { Tüketim } \\
\text { alışkanlıkları }\end{array}$ \\
\hline 7.Hafta & $\begin{array}{l}\text { Toprağı, suyu, } \\
\text { bitkileri seviyorum: } \\
\text { Onlarla yeni formlar } \\
\text { yaratıyorum }\end{array}$ & $\begin{array}{l}\text { Kil, su ve } \\
\text { doğal bitkiler }\end{array}$ & $\begin{array}{l}\text { Doğal kaynakları } \\
\text { koruma } \\
\text { Nesiller arası eşitlik }\end{array}$ & $\begin{array}{l}\text { klim } \\
\text { değişikliği } \\
\text { Kuraklık }\end{array}$ \\
\hline 8.Hafta & $\begin{array}{l}\text { Perspektifi yok et, } \\
\text { komediyi keşfet }\end{array}$ & $\begin{array}{l}\text { Dijital fotoğraf } \\
\text { makinası ile } \\
\text { doğada keşifler }\end{array}$ & $\begin{array}{l}\text { Ortaklaşa çalışma } \\
\text { Barış ve tolerans } \\
\text { kültürünü destekleme }\end{array}$ & şbirliğ \\
\hline 9.Hafta & $\begin{array}{l}\text { Andy Goldsworhty ve } \\
\text { doğada sanat, doğayla } \\
\text { sanat }\end{array}$ & $\begin{array}{l}\text { Taş, yaprak, } \\
\text { dal gibi doğal } \\
\text { materyaller }\end{array}$ & $\begin{array}{l}\text { Çevreyi koruma ve } \\
\text { onu iyileştirme } \\
\text { Doğal kaynakları } \\
\text { koruma }\end{array}$ & $\begin{array}{l}\text { Doğanın } \\
\text { güzellikleri }\end{array}$ \\
\hline 10.Hafta & Bir sanatçıyla söyleşi & Sanat eserleri & $\begin{array}{l}\text { Kültürel } \\
\text { sürdürülebilirliği } \\
\text { destekleme }\end{array}$ & $\begin{array}{l}\text { Kültürel } \\
\text { değerler }\end{array}$ \\
\hline
\end{tabular}

Tablo 1'de görüldüğü gibi doğa ve çevre üzerine kurulan her bir etkinlik aynı zamanda toplum ve ekonomi boyutları kapsamında sürdürülebilir kalkınma eğitiminin altını çizdiği nesiller arası eşitlik, kültürel sürdürülebilirliği destekleme, barış ve tolerans kültürünü destekleme, çevreyi koruma ve onu iyileştirme ve doğal kaynakları koruma gibi konulara bağlanmıştır. Etkinliklerin genel amacı; Şengül'ün (2001) çevre eğitiminin beklenen 
işlevlerinin sağlanması üzerine kurulmuştur. Bunlar: 1) Çevre hakkında bilgilendirme, 2) Çevre için duyarlılık yaratmak ve 3) Çevre için davranış değişikliği yaratmaktır.

Sürdürülebilirliği öğretim etkinliklerine bütünleştirirken sürdürülebilir kalkınma eğitiminin yapısını oluşturan; bilgi, konu, bakış açısı, beceri ve değer sürdürülebilirliğin üç temel yapı taşı olan toplum, ekonomi ve çevre bağlamında ele alınmıştır. Örneğin; Tablo 1'de 6. Hafta etkinliği olarak gösterilen "Atıktan Sanata” adlı etkinliğin yapılandırılması Şekil 2'de sunulan sistemsel yaklaşım temel alınmıştır.

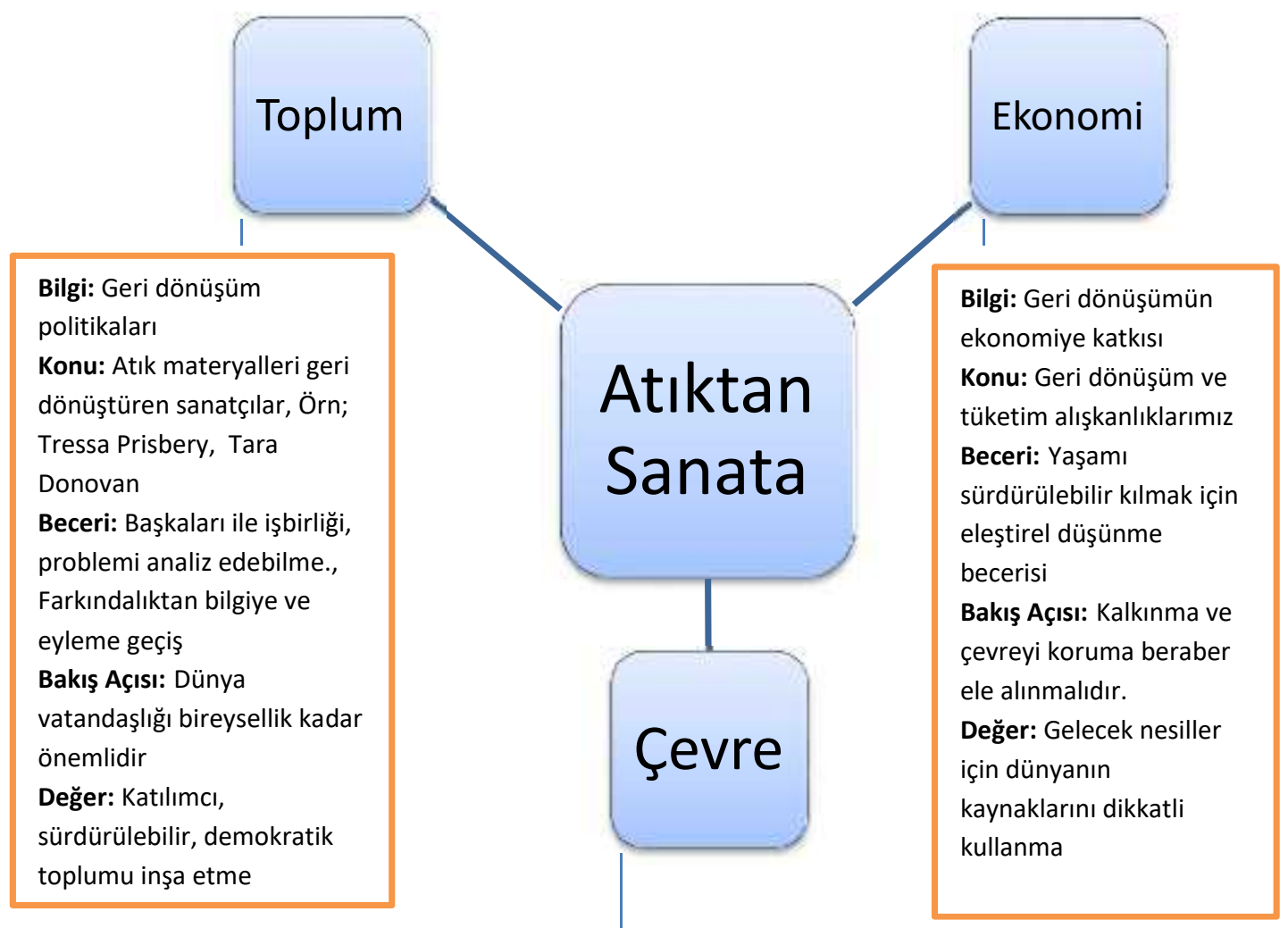

Bilgi: Atıkların doğada yok olma süreleri (Plastik, cam, kağıt, metal vs.), Atıkların doğadaki biyoçeşitliliğe etkileri (Örn; deniz yaşamının azalması, içme suyu kaynaklarının kirlenmesi)

Konu: Geri dönüşüm yoluyla sanat uygulamaları, Ekolojik Sanat Uygulamaları

Beceri: Yaşamı sürdürülebilir kılmak için eleştirel düşünme becerisi, çevre ve sanat üzerine estetik bilinci destekleme

Bakış Açısı: Yerel konular küresel bağlamda anlaşıımalıdır, yerel problemlere çözümün küresel sonuçları vardır. Değer: Gelecek nesiller için dünyanın güzellikleri güvenceye alma

\section{Şekil 2. Bir ders etkinliğinin sürdürülebilir kalkınma ĕgitimi çerçevesinde}

\section{yapılandırılması}

Her etkinlik Şekil 2'de örnek olarak sunulan sürdürülebilir kalkınma eğitim modeline göre yapılandırılmıştır. Öğretim süreci doğa, insan ve çevre bilimlerini kapsayacak şekilde disiplinler arası bilgiyle yapılandırılmıştır. Ayrıca doğayla etkileşimin ağırlık kazandığı 
tartışma, sorun analizi, sanat eseri analizi, demostrasyon, işbirlikli öğrenme gibi öğretim teknikleri ile çeşitlendirilmiştir.

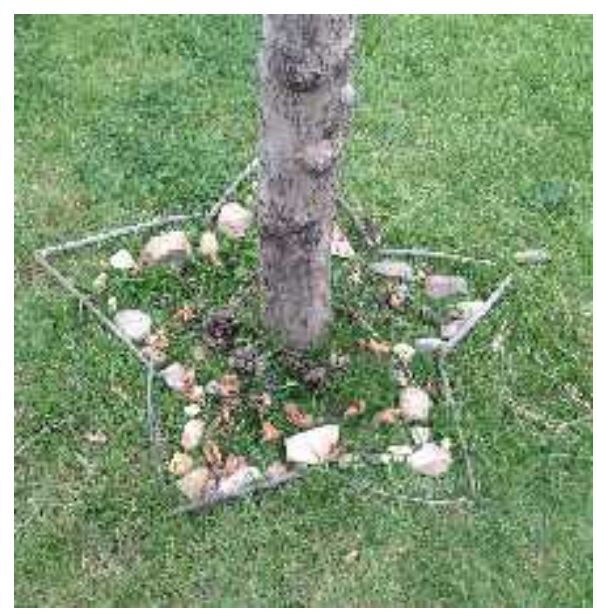

Resim 1. Öğrenci çalışması

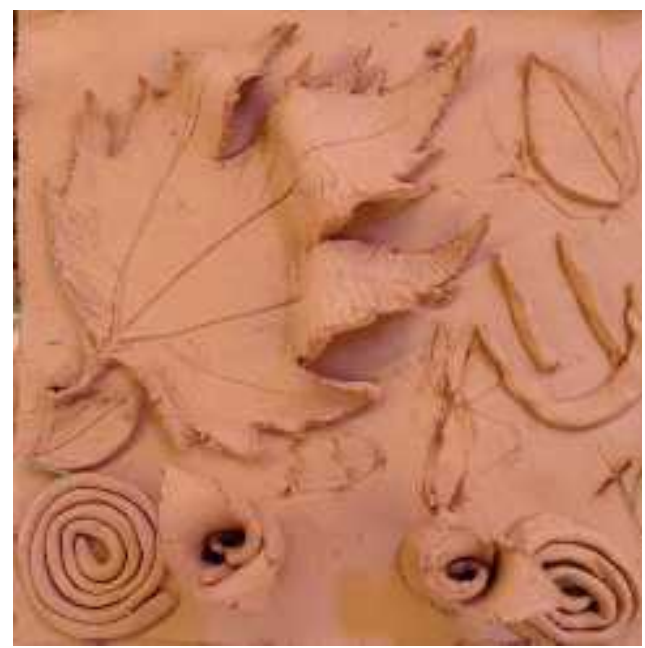

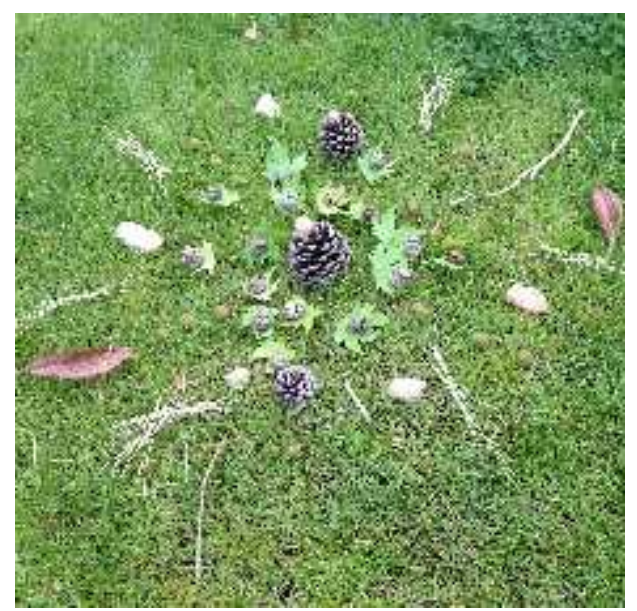

Resim 2. Öğrenci çalışması

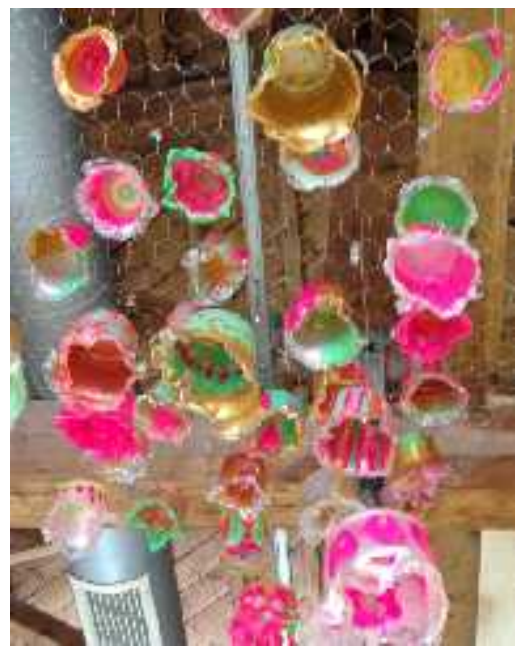

Resim 3. Öğrenci çalışması

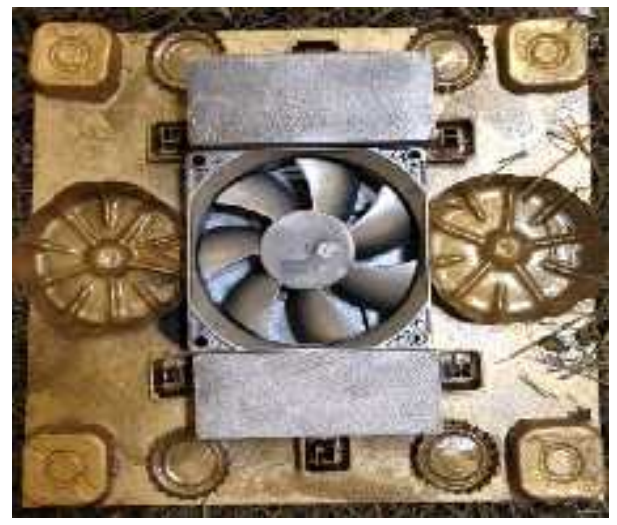

Resim 5. Öğrenci çalışması

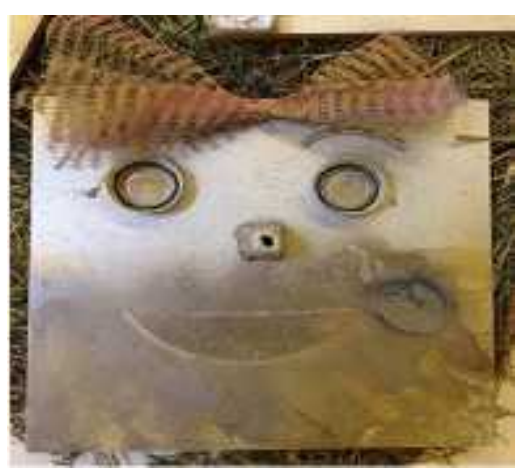

Resim 6. Öğrenci çalışması 
Araştırmada "Sürdürülebilir kalkınma ĕgitimi bağlamında hazırlanan sanat aktivitelerinin öğrencilere katkısı nelerdir?” sorusu ders sürecinde öğrencilerin öz değerlendirme yazılarından ve süreç sonunda uygulanan yarı yapılandırılmış ve açık uçlu soruların yer aldığı değerlendirme formundan elde edilmiştir. Bulgular öğrencilerin ders süreci hakkında düşünceleri ve sürdürülebilir kalkınma eğitimi bağlamında hazırlanan sanat aktivitelerinin öğrencilere katkısı olarak iki tema altında sunulmuştur. Öğrencilerin ders süreci hakkındaki düşünceleri Tablo 2'de verilmiştir.

Tablo 2. Öğrencilerin ders süreci hakkındaki düşünceleri

\begin{tabular}{lcc}
\hline Sanat etkinliklerinde en çok neleri sevdin? (Birden fazla seçenek işaretleyebilirsin) & \\
\hline Özgür ifade ortamını & 11 & $\% 55$ \\
Etkinliklerin merak uyandırmasını & 13 & $\% 65$ \\
Doğal çevreyle ve gerçek yaşamla bağlantılar kurulmasını & 16 & $\% 80$ \\
Arkadaşlarımla gerçekleştirdiğim ortak çalışmaları & 11 & $\% 55$ \\
Okuldan daha farklı bir öğrenme ortamı sunulmasını & 12 & $\% 60$ \\
Öğretmenlerimle ve arkadaşlarımla daha fazla etkileşim fırsatını & 11 & $\% 55$ \\
Gerçek bir sanatçılla eserleri üzerinden konuşmayı & 16 & $\% 80$ \\
Gelecek üzerine düşünmeyi & 14 & $\% 70$ \\
Ağaç dikerek doğaya katkı sağlamayı & 20 & $\% 10$ \\
\hline Buradaki sanat çalışmalarında öğrendikleriniz konusunda neler hissediyorsun? & \\
\hline Çok şey öğrendiğimi düşünüyorum & 18 & $\% 90$ \\
Biraz öğrendiğimi düşünüyorum & 2 & $\% 10$ \\
Hiçbir şey öğrenmediğimi düşünüyorum & - & - \\
Diğer & - & - \\
\hline Öğrenme ortamı senin için nasıldı? (Birden fazla seçenek işaretleyebilirsin) & & \\
\hline Zorlayıcı & - & - \\
Keyifli & 15 & $\% 75$ \\
Merak uyandırıcı & 17 & $\% 85$ \\
Yeni deneyimlerle öğretici & 9 & $\% 45$ \\
Düşündürücü & 3 & $\% 15$ \\
şbirlikli-Ortak & 14 & $\% 70$ \\
Okul derslerimi destekleyici & 8 & $\% 40$ \\
Diğer: Malzemeleri ortaklaşa kullanmak & 3 & $\% 15$ \\
\hline Proje etkinliklerinde hoşlanmadığın şeyler nelerdir? & & \\
\hline "Yok” & 16 & $\% 80$ \\
"Her etkinlik sonrası form doldurmak” & 3 & $\% 15$ \\
\hline Bazı etkinliklerin zor olmasından” & 1 & $\% 5$ \\
\hline
\end{tabular}

Araştırma bulgularına göre öğrencilerin hemen hemen tamamı doğayla etkileşim, gerçek yaşamla bağlantı ve geleceği düşünme konusunda projeye karşı olumlu görüş bildirmişlerdir. Öğrenciler proje sürecinde çok şey öğrendiklerini düşünmektedir. Öğrencilerin projede en çok sevdiği şeyler: ağaç dikerek doğaya katkı sağlamak, bir sanatçıyla, doğal çevreyle ve gerçek yaşamla etkileşime girmektir. Ayrıca etkinliklerin merak uyandırıcı nitelikte olması, özgür ve okuldan daha farklı bir öğrenme ortamı sunulması 
öğrencilerin hoşlandığı şeylerdendir. Öğrencilerin büyük bir kısmı öğrenme ortamını merak uyandırıcı ve keyifli olarak nitelendirmiştir. Ortak ve işbirliği içinde çalışma öğrencilerin öğrenme ortamına ilişkin tespitlerindendir.

Öğrencilerin görüşlerine daha yakından bakıldığında ise, sanat aktivitelerinin öğrencilere katkısı altı kod altında çözümlenmiştir. Bunlar; 1) Sanat yoluyla doğayla etkileşim, 2) Çevre üzerine yeni fikir ve değerlerin gelişimi, 3) Çevreyi sanat yoluyla koruma bilinci, 4) Gelecek nesillere dair farkındalık, 5) Çevresel bozulmaya dair farkındalık, 6) Sanatın farklı boyutlarını ve anlamlarını keşfetme' dir. Kod ve öğrenci görüşlerinden bir kısmı Tablo 3'de sunulmuştur.

Tablo 3. Sürdürülebilir kalkınma e ğitimi bă̆lamında hazırlanan sanat aktivitelerinin ögrencilere katkısı

\begin{tabular}{|c|c|}
\hline Kodlar & Öğrenci görüşleri \\
\hline $\begin{array}{l}\text { Sanat } \\
\text { yoluyla } \\
\text { doğayla } \\
\text { etkileşim }\end{array}$ & 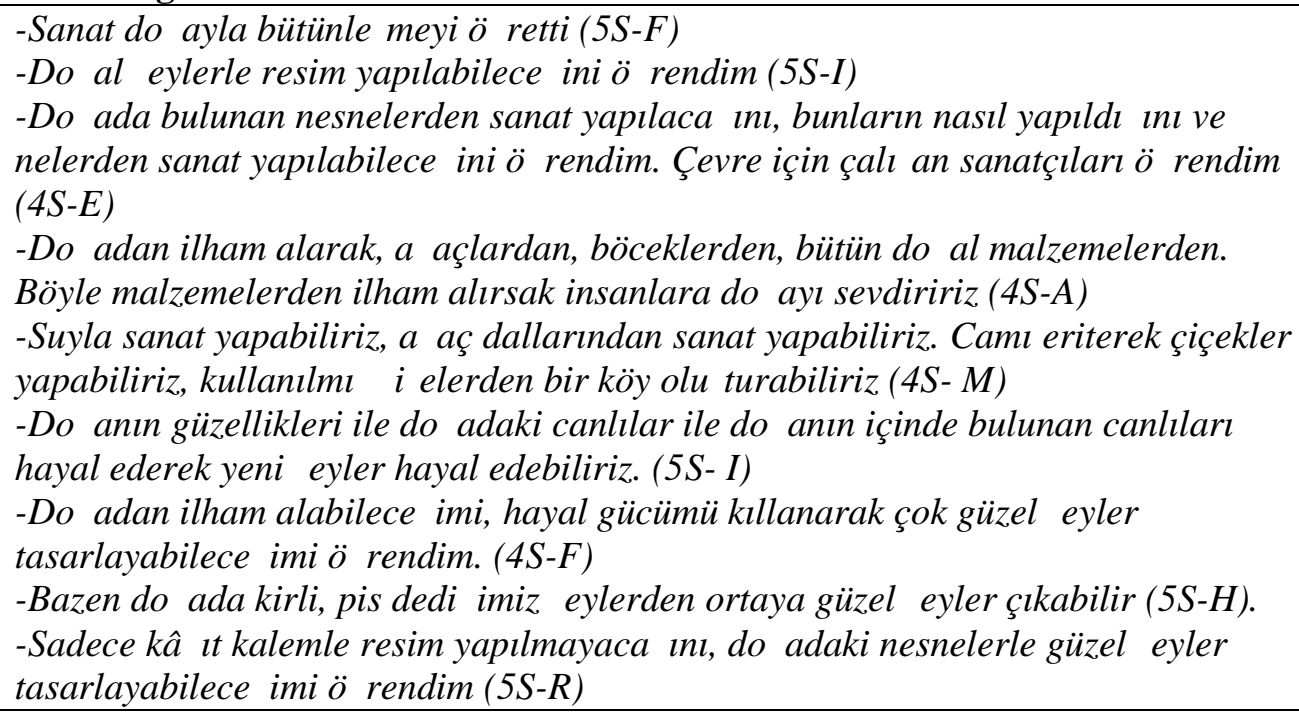 \\
\hline $\begin{array}{l}\text { Çevre } \\
\text { üzerine yeni } \\
\text { fikir ve } \\
\text { değerlerin } \\
\text { gelişimi }\end{array}$ & $\begin{array}{l}\text {-Çevremizi sanatta olduğu gibi atıkları geri dönüş̧ürerek koruyabiliriz. Doğaya } \\
\text { zarar vermeyen malzemeler kullanarak koruyabiliriz }(4 S-E) \\
\text {-Çevremizdeki her şeyin aslında gereksiz olmadığını öğrendim (4S-A) } \\
\text {-Çöplerin geri dönüsüm olanlarını mutlaka ayırmaltyız }(5 S-H) \\
\text {-Oksijeni kaybetmemek için doğayı korumalıyız. Geri dönüştürülebilen maddeleri } \\
\text { geri dönüşüme atmalıyız }(4 S-H)\end{array}$ \\
\hline $\begin{array}{l}\text { Çevreyi } \\
\text { sanat } \\
\text { yoluyla } \\
\text { koruma } \\
\text { bilinci }\end{array}$ & 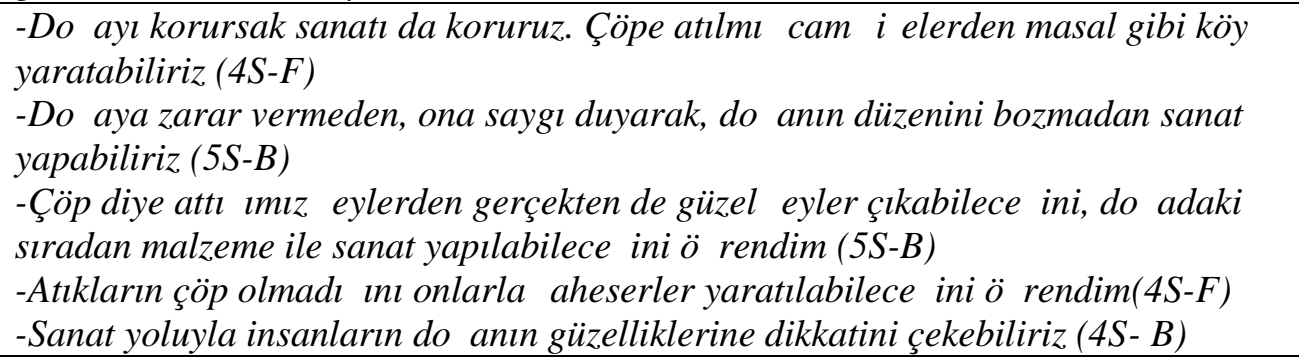 \\
\hline $\begin{array}{l}\text { Gelecek } \\
\text { nesillere } \\
\text { dair }\end{array}$ & $\begin{array}{l}\text {-Çevremiz ve doğa bizim yaşam kaynă̆ımızdır. Onu koruyamazsak ne kendimize ne } \\
\text { de gelecek nesillere iyilik yapmış oluruz }(4 S-E) \\
\text {-Gelecek nesillere doğa bırakmak için }(4 S-A)\end{array}$ \\
\hline
\end{tabular}




\begin{tabular}{|c|c|}
\hline farkındalık & $\begin{array}{l}\text {-Doğayı gelecekte yaşayacaklar için korumalıyı (4S-D) } \\
\text {-Geleceği güzelleştirmek için doğayı korumalıyı }(5 S-M)\end{array}$ \\
\hline $\begin{array}{l}\text { Çevresel } \\
\text { bozulmaya } \\
\text { dair } \\
\text { farkındalık }\end{array}$ & $\begin{array}{l}\text {-Çevremizi korumazsak, bizim sağlı̆̆ımız bozulabilir }(4 S-F) \\
\text {-Çevremizi korumazsak hayvanlara zarar vermiş oluruz, hayvanların yaşamasını } \\
\text { engelleriz, kendi sağllğımızı tehlikeye atar hasta oluruz }(4 S-C) \\
\text {-Çöpleri değerlendirirsek dünya için daha güzel şeyler yapabiliriz }(4 S-F) \\
\text {-Dünyamızdaki çöpler tekrar kullanılmazsa dünyamızın bir çöp ülkesi olacağını }(4 S- \\
\text { B) }\end{array}$ \\
\hline $\begin{array}{l}\text { Sanatın } \\
\text { farklı } \\
\text { boyutlarını } \\
\text { ve } \\
\text { anlamlarım } \\
\text { keşfetme }\end{array}$ & 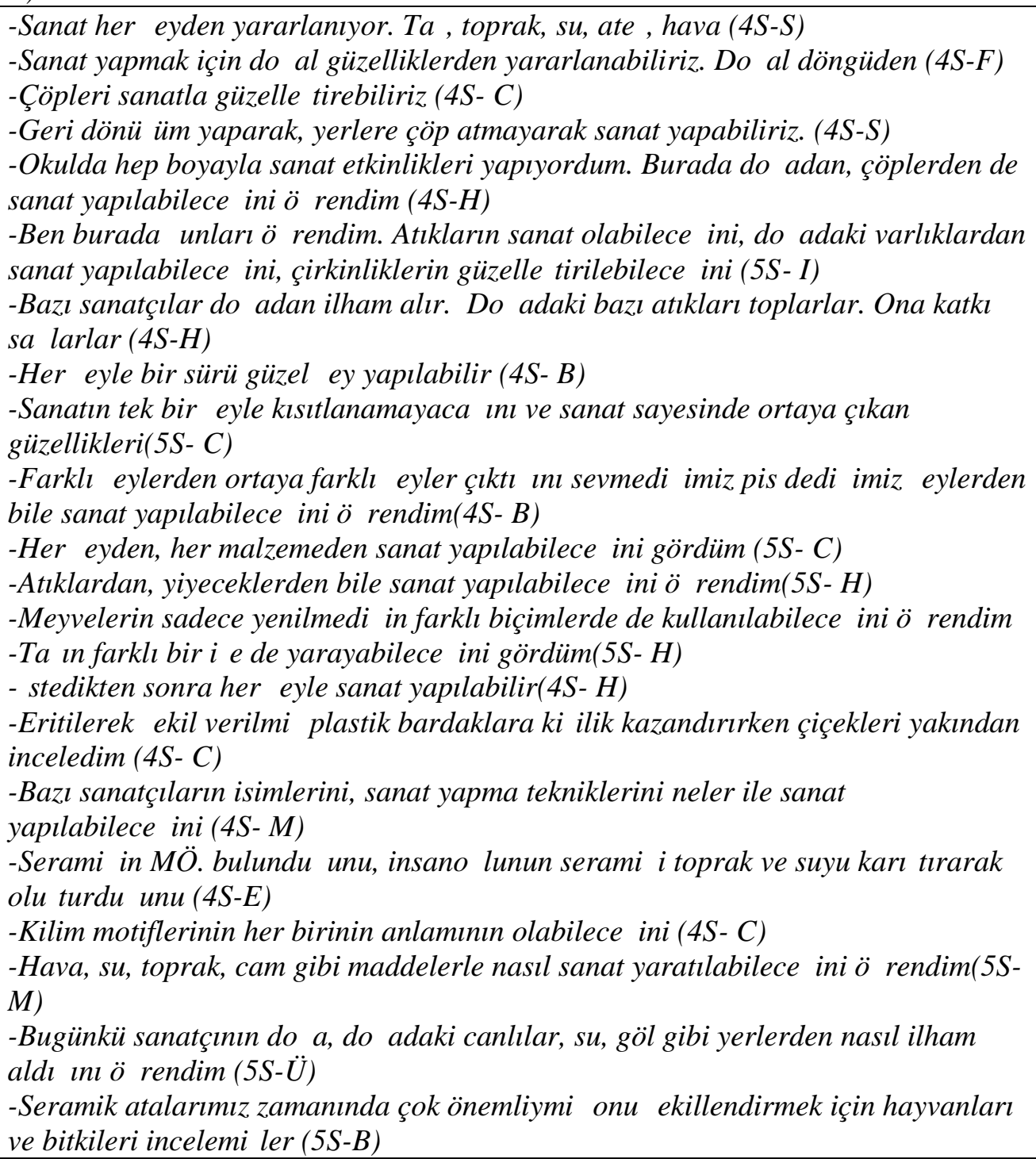 \\
\hline
\end{tabular}

Tablo 3'te öğrenci ifadelerinde görüldüğü gibi, doğayı izleme, ondan ilham alma, sanat materyali olarak yararlanma ve onu güzelleştirmeye dönük düşünceler sürdürülebilir kalkınma eğitimi destekli sanat uygulamalarının doğayla etkileşimi ve uyumu arttırdı̆̆ şeklinde görülebilir. Ayrıca öğrencilerin geri dönüşüm, tüketimde doğaya zarar vermeyen malzeme tercihi, doğadaki her şeyin önemini anlamaya dair ifadeleri çevre üzerine yeni fikir ve değerlerin gelişimine hizmet eden kazanımlardır. Öğrencilerin çevrenin sanat yoluyla korunabileceğine ilişkin fikirleri vardır. Dünyadaki çöplerin artmasına bağlı olarak insan ve 
canlı sağlığının bozulmasına dair endişeler çevresel bozulmaya farkındalığı getirdiği gibi gelecek nesiller için doğayı korumaya dair fikirlerin gelişimine neden olmuştur.

Sürdürülebilir kalkınma destekli sanat uygulamaları öğrencilerin sanatın farklı boyutlarını ve anlamlarını keşfetmelerine yardım ettiği görülmektedir. Sanattaki malzeme çeşitliliği, farklı materyallerin farklı sonuçlar oluşturması, sanatın sınırsızlığı, sanatçıların geri dönüşüme katkısı, çirkinliklerin sanat yoluyla güzelleştirilebileceği ve sanatçıya doğanın nasıl ilham verdiği üzerine gelişen fikirler öğrencilerin ifadelerinde yer almaktadır. Bu ifadeler araştırmanın öğrencilere bilişsel, duyuşsal ve sosyal bağlamda ekolojiyi koruma sorumluluğuna katkı sağlama potansiyelinin yüksek olduğu gösterir niteliktedir.

\section{Sonuç ve Tartışma}

Örgün ve yaygın eğitim kurumlarında bireylere eğitim yoluyla kazandırılacak bilgi ve beceriler sürdürülebilir toplumlar için kilit rol oynamaktadır (Lenz, 2013). UNESCO programlarında bir toplumun varlığının sürdürülebilir bir çevre olmadan sağlanamayacağı ifade edilmektedir. $\mathrm{Bu}$ nedenle son yıllarda çevre eğitimi sürdürülebilir kalkınmanın gerçekleşebilmesi açısından üzerinde çalışılan önemli konulardan biri haline gelmiş, "çevre için eğitim", “ekoloji pedagojisi”, "ekolojik öğrenme” ve "doğa deneyimi” gibi çeşitli kavramsal yapılarla alan yazında farklı biçimlerde adlandırılmıştır. Ancak son yıllarda toplum, ekonomi ve çevre üçlemesi altında daha kapsayıcı ve bütüncül bir zeminde ele alınarak "sürdürülebilir kalkınma için eğitim” olarak kabul görmüştür. Bu bağlamda eğitim programlarının sürdürülebilir bakış açısına göre çağın gereksinimlerine de uygun olarak yeniden yapılandırılması gündeme gelmeye başlamıştır. Nitekim Avrupa Birliği’ne bağlı ülkelerin sanat ve kültür eğitiminin incelendiği Education, Audiovisual and Culture Executive Agency (2009) raporunda "Çevresel farkındalık ve sürdürülebilirlik" kavramlarının 20 ülkenin sanat öğretim programının amaçlarına girdiği görülmektedir. Araştırma kapsamında 35 Avrupa ülkesinden 20'sinde "fiziki çevrenin değerini bilme", "sanat malzemelerinin kaynağını anlama" ve "ekolojiyi koruma sorumluluğu" nun programların temel amaçlarında detaylandırıldığı tespit edilmiştir. Ülkemizde özellikle nüfus artışı ile birlikte görülen sanayileşme, sağlıksız kentleşme ve hızlı ekonomik gelişme başta hava, su ve toprak kirliliği olmak üzere erozyon, tarım ve orman arazilerinin kaybı gibi çevre sorunlarına neden olmuştur. Su fakiri ülkeler arasında yerini alan Türkiye sadece 'büyümeye' odaklı plansız yatırımlar ile son 50 yılda sulak, tarım ve orman arazilerinin büyük çoğunluğunu kaybetmiştir (Mamur ve Köksal, 2016). Bu çevre sorunları ise giderek doğal yaşamın bozulmasına neden 
olmaktadır. Dolayısıyla sürdürülebilir bakış açısının Avrupa ülkelerinin pek çoğunun sanat programında yer aldığı gibi Türkiye'de de sanat öğretim programlarında daha fazla yer verilmesi gerektiği düşünülmektedir.

$\mathrm{Bu}$ araştırmada sürdürülebilir kalkınmanın sürdürülebilir bir çevre olmadan sağlanamayacağı düşüncesiyle öğretim programı ağırlıklı olarak çevre ve doğa bağlamında yapılandırılmıştır. Öğrencileri bağlamsal ve sezgisel düşünmeye yöneltmek için doğa ve çevre temelli sanatçı çalışmaları, üretimde doğal ve atık malzeme tercihi ve doğada çeşitli uygulama çalışmaları nesiller arası eşitlik, geri dönüşüm politikaları, suyun ve toprağın kullanımı, tüketim alışkanlıkları gibi konularla ilişkilendirilmiştir. Böylelikle çevreye dönük gerekli biliş, duyuş ve davranış değişikliğinin sağlanması amaçlanmıştır. Araştırma bulgularına göre proje çerçevesinde gerçekleşen sanat etkinliklerinin; doğayı tanıma ve önemini anlama, doğaya ve çevreye sanatın getirdiği güzellikleri fark etme, sanattaki çeşitliliği keşfetme noktasında katkı sağladığı tespit edildiği gibi onu düzeltmeye dönük istekliliğe neden olduğu görülmüştür. Öğrenciler her şeyden sanat yoluyla güzel şeyler yaratılabileceğine dair fikirler geliştirmişler, gelecek nesillerle empati kurabilme ve çevre sorunlarını çok yönlü algılama ve gelecek üzerine daha iyi bir yaşam düşünmeye dair tutumlar göstermişlerdir. Buradan hareketle sanat eğitimine yönelik şu öneriler getirilebilir:

-Sürdürülebilir kalkınma eğitimi herhangi bir disiplinin tek başına sahiplenebileceği bir yaklaşım değildir. Sosyal bilimlerden, fen bilimlerine ve sanata kadar her disiplin kendi perspektifinden sürdürülebilir bakış açısını öğrencilere kazandırabilir.

-Öğrencilerin yaşadıkları bölgeyle ilgili farkındalığını artırmak, disiplinler arası çalışmayı gerektirmektedir.

- Öğrencilerin doğa sevgisi kazandırma ve çevreye karşı farkındalıklarını artırmak için doğada uygulamalı sanat faaliyetleri büyük önem taşımaktadır.

- Sanat öğretim programlarında toplumsal, kültürel ve ekolojik restorasyonla ilgili çalışan sanatçıların çalışma prensipleri ve sanat üretimlerinden yararlanılabilir.

-Öğrencileri doğal çevrenin yanında kültürel çevrenin sanatçıları ve eserleri ile karşılaştırma kültürel sürdürülebilirlik açısından önemlidir.

- Sürdürülebilir kalkınma eğitiminin konu alanlarından olan "sosyal adalet”, “ sosyal yargılar", sürdürülebilir demokratik toplum”, "toplumsal cinsiyet eşitliği” gibi toplumsal konular ile "tüketim alışkanlıkları" gibi ekonomiyle ilişkilendirilebilecek konular sanat eğitiminde görsel kültür kuramı perspektifinde irdelenebilir. 


\section{Kaynaklar}

Alkış, S. (2007). Coğrafya eğitiminde yükselen bir paradigma: Sürdürülebilir bir dünya. Marmara Coğrafya Dergisi, 15(55-64).

Bafra, Ç. ve Colombo, P. (2016). Yok olmadan. C. Kantarc1 (Ed.) Yok olmadan doğa ve sürdürülebilirlik üzerine bir sergi (ss. 15-26) içinde, stanbul: stanbul Modern.

Beyhan, A. (2013). Eğitim örgütlerinde eylem araştırması. Bilgisayar ve Ĕ̆itim Araştırmaları Dergisi, 1(2)65-89.

Education, Audiovisual and Culture Executive Agency, (2009). Avrupa'da okullarda sanat ve kültür eğitimi. http://www.eurydice.org, adresinden 27.08.2016 tarihinde elde edilmiştir.

Heinberg, R. (2016). Neden sürdürülebilirlik?, C. Kantarcı (Ed.) Yok olmadan doğa ve sürdürülebilirlik üzerine bir sergi (ss. 27-36) içinde, stanbul: stanbul Modern.

Hollis, C. L.(1997). On developing an art and ecology curriculum. Art Education, 50 (6), 2124.

Kaya, M. F. ve Tomal, N. (2011). Sosyal bilgiler dersi öğretim programının sürdürülebilir kalkınma eğitimi açısından incelenmesi. Eğitim Bilimleri Araştırmaları Dergisi Journal of Educational Sciences Research, 1(2), 49-65.

Krippendorff, K. (2004). The content analysis reader. K. Krippendorff and M.A. Bock (Eds.), In Testing there liability of content analysis data: What is involved a why (pp. 350-358), Los Angeles, CA: Sage Publications.

Lenz, C. (2013). Sürdürülebilir demokratik toplumlar için eğitimin kilit rolü. Çev.: Mine Gözübüyük Tamer, Hitit Üniversitesi Sosyal Bilimler Enstitüsü Dergisi, 6(2), 103-110.

Mamur, N.ve Köksal N. (2016). Görsel sanatlar öğretim programının sürdürülebilir kalkınma eğitimi bağlamında incelenmesi. Bartın Üniversitesi Ĕ̆itim Fakültesi Dergisi, 5(3)732747.

Miles, M. B. ve Huberman, A. M. (1994). Qualitative data analysis: An expanded sourcebook. Sage Publications, Thousand Oaks, CA

Neperud, R. W. (1997). Art, ecology ve art education: Practices and linkages. Art Education, 50(6), 14-20. 
Öztürk Demirtaş, Ç. (2011). Coğrafya dersi öğretim programında sürdürülebilir kalkınma. Uluslararası nsan Bilimleri Dergisi, 8(2), 595-615.

Özdemir, O. (2007). Yeni bir çevre eğitimi perspektifi: Sürdürülebilir gelişme amaçlı eğitim. Ĕ̈itim ve Bilim, 32(145), 23-39.

Strankiewicz, M. A. ve Krug, D. H. (1997). Art and ecology. Art Education. 50 (6), 4-5.

Şengül, M. (2001). Bir çevre yönetimi aracı olarak çevre için eğitim. Amma daresi Dergisi, 34(4), 137-155, Ankara.

Tanrıverdi, B. (2009). Sürdürülebilir çevre eğitimi açısından ilköğretim programlarının değerlendirilmesi. Ĕ̆itim ve Bilim, 34(151), 89-103.

Teksöz, G., Şahin, E. ve Ertepınar, E. (2010). Çevre okuryazarlığı, öğretmen adayları ve sürdürülebilir bir gelecek. Hacettepe Üniversitesi Eğitim Fakültesi Dergisi, 39, 307320.

The United Nations Economic Commission for Europe, (2009). The UNECE strategy for education for sustainable development, United Nations: New York and Geneva. https://sustainabledevelopment.un.org/content/documents/798ece5.pdf adresinden 18.06.2016 tarihinde elde edilmiştir.

United Nations Educational, Scientific and Cultural Organization, (2005). United Nations decade of education for sustainable development (2005-2014): International implementation scheme, Paris: UNESCO.

https://www.bibb.de/dokumente/pdf/a33_unesco_international_implementation_scheme .pdf adresinden 18.06.2016 tarihinde elde edilmiştir.

United Nations Educational, Scientific and Cultural Organization, (2012). Education for sustainable development, Paris: United Nations Educational Scientic and Cultural Organization, https://sustainabledevelopment.un.org/content/documents/926unesco9.pdf adresinden 18.06.2016 tarihinde elde edilmiştir. 


\section{Extended Abstract}

The scope of environmental problems that threaten health in the world is increasing day by day. The fact that humans have done irreversible damage on environment has brought many problems. For example natural resources have been consumed, glaciers have been melting, drinking water resources have been polluted, the sea levels have risen, there have been problems in the ecosystem and new diseases have occurred. Precautions against this damage recognized after the second half of the 20th century, were only discussed after 1970s in a multidimensional way. Learning to live within nature through a sustainable way within the frame of environment, society and economy has been emphasized more as a cultural responsibility and therefore, the need for main area practices of sustainability in education has increased. Art and art education have started to focus on sustainability in terms of how to deal with the changing world and how they can contribute to it. Because, art education is in a location where it can raise the awareness of environmental corruption as it is the touch point between nature and social life. In this context, World Arts Education Union founded by UNESCO by uniting international art education associations (InSEA, IDEA, ISME, WDA) pointed out that art education programs should be structured in terms of increasing awareness of biological, social and cultural variety, improving social justice, ecological and environmental awareness within the context of "Art Education for Sustainable Development".

In this study, activities that aim children to discover themselves, social environment and environment through art were developed based upon sustainability and it was aimed to figure out the effects of these activities on children. The research is an action research that can provide a guide to visual arts teachers about how to build an art course and how to design art activities in the context of sustainability. There were 20 students between the ages of 10-11 in the study. 11 of the participants were $4^{\text {th }}$ grade students and 9 of them were $5^{\text {th }}$ grade students. Research data were collected by self-assessment essays written by students and process evaluation forms filled by the students after each activity and analyzed by content analysis.

Research findings showed that sustainable development based art activities, increased the understanding of the interactions between art and science, art and nature, recycling waste materials in a new and aesthetic way; and environmental deterioration awareness. The research findings showed that sustainable development-based arts activities raise awareness regarding environmental degradation, understanding of interaction between art and science, art and nature, re-evaluation of waste materials in an aesthetic way. In the research, the teaching program was structured largely in the context of environment and nature, with the 
idea that sustainable development cannot be achieved without sustainable environment. Art works based on nature and environment were associated with topics such as the choice of natural and waste materials in production and various art activities in nature, the equality between generations, recycling policies, the use of water and soil, consumption habits to encourage students to think contextually and intuitively. Thus, it was aimed to provide the change of cognition, perception and behavior concerning the environment. According to research findings, it was found that the art activities taking place in the framework of the project contribute to the point of recognizing nature and understanding its importance, realizing the beauties brought by nature to the environment, discovering the diversity in nature as well as the willingness to correct it. Students developed new ideas about art and showed attitudes on developing empathy with future generations and perceving environmental problems in a multifaceted way and thinking about a better life in the future.

Increasing students' awareness related the region they live in requires interdisciplinary works. Sustainable development education is not an approach that any discipline can take on its own. Every discipline, from social sciences to physical sciences and art, can gain students a sustainable perspective. Furthermore, it is important to bring together with the artists of the cultural environment and their artworks beside the natural environment in terms of cultural sustainability. Practical arts activities in nature are important to gain students love of nature and increase their awareness towards the environment. Social issues such as "social justice", "social judiciary", "sustainable democratic society", "gender equality" and issues that can be associated with the economy such as "consumption habits", which are the subject areas of sustainable development education, can be examined in the perspective of visual culture theory in art education. 